\title{
O FUNCIONAMENTO DA AUTORIA NOS BLOGS DE DIVULGAÇÃO CIENTÍFICA*
}

\author{
Simone de Mello de Oliveira**
}

Resumo: Este artigo se propõe a pensar o funcionamento discursivo dos blogs de divulgação científica, colocando em questão o modo de constituição da autoria, no contexto das Novas Tecnologias da Informação e da Comunicação (NTICs). Para tanto, analisamos os blogs de divulgação científica do Anel de Blogs Científicos da USP e recortamos os posts sobre a $61^{\circ}$ Reunião Anual da SBPC. Tomamos como procedimentos de análise aqueles apresentados pela Análise de discurso de linha francesa. E a partir da análise, podemos observar um funcionamento que incorpora uma prática da internet, que é o copiar e colar, e que representa uma apropriação de textos pelo blogueiro; apaga-se o fato de o texto ser de outra pessoa. Logo, não lidamos mais com um autor como origem do dizer.

Palavras-chave: Autoria. Blogs. Divulgação científica.

\section{INTRODUÇÃO}

Vamos nos ocupar, neste texto, da análise dos blogs de divulgação da ciência que abordaram em seus posts a $61^{\text {a }}$ Reunião Anual da Sociedade Brasileira para o Progresso da Ciência, ocorrida nos dias 12 a 17 de junho de 2009, em Manaus/AM, com a temática "Amazônia Ciência e Cultura".

Trabalhando na perspectiva da Análise de Discurso, estudamos a constituição, formulação e circulação do discurso sobre a ciência através dos blogs de divulgação. E assim, analisando o funcionamento discursivo desses blogs, colocamos em questão o modo de constituição da autoria, no contexto das Novas Tecnologias da Informação e da Comunicação (NTICs).

Nossa questão norteadora diz respeito ao modo como se constitui a posição- sujeito divulgador de ciência nesse espaço discursivo, no qual temos uma tecnologia de linguagem produzindo um tipo específico de

\footnotetext{
* Texto apresentado à banca de qualificação de área, PPGL-IEL (UNICAMP), sob a supervisão da professora Cláudia Pfeiffer, e utilizado em parte para a tese Os blogs de divulgação científica: informação, noticia e divulgação, sob a orientação do professor Eduardo Guimarães.

** Doutor em Linguística pela UNICAMP. Bolsista CAPES 07/08. Pesquisadora do Laboratório Corpus/UFSM - Bolsista PNPD/Capes. Email: simone.mo@gmail.com.
} 
texto, com hiperlinks, etc. e uma discursividade, com sujeitos e processos de significação afetados pela relação com a tecnologia.

Dessa forma, problematizamos a relação discurso e sociedade sob o ponto de vista das práticas discursivas, sendo estas analisadas em um novo espaço social e urbano, o ciberespaço. Assim, procuramos compreender como os blogs de divulgação científica funcionam em sua discursividade, como eles produzem sentido.

Nosso percurso para empreendermos tal trabalho começa obrigatoriamente pela constituição do que hoje são os blogs, e mais especificamente, os blogs de divulgação científica e seu funcionamento no ciberespaço, o que coloca também em questão a noção de ciberespaço. A constituição do corpus também será afetada por essa questão, assim como o recorte do objeto e a análise propriamente dita. Isso tudo a partir do prisma do gesto de leitura mediado pela tecnologia. Faremos isso por meio de uma metáfora, que é o movimento fotográfico de zoom e de afastamento do gesto de aproximar e afastar o olhar, através do movimento de zoom.

\section{ZOOM 1 - OS BLOGS E O CIBERESPAÇO}

Para adentrarmos o universo dos blogs de divulgação, entendemos necessário fazer um percurso que vai desde o diarismo até a prática atual dos blogs. Para tanto, começamos por um momento que consideramos importante para o surgimento dos weblogs.

Em fins dos anos 1990, Philippe Lejeune (2000) publicou em um jornal francês (Lire', junho de 1998) uma demanda por depoimentos de diaristas (pessoas que mantinham diários íntimos) que estavam vivendo a experiência de passar da escrita no papel para o computador. Sua enquete tratava das novas formas de se relacionar com a escrita íntima na era do computador pessoal.

Em um segundo momento de seu trabalho, o autor percebeu que, ao considerar somente os diários escritos no computador, estava deixando de lado algo muito importante que surgia naquele momento, os

\footnotetext{
${ }^{1}$ Lire é uma revista francesa mensal de literatura fundada em 1975 por Jean-Louis Servan-Schreiber e Bernard Pivot.
} 
diários on-line, publicados na internet. $\mathrm{O}$ autor já havia tentado por várias vezes incursões pelos diários on-line, mas sempre com impressões negativas: "lorsqu'on vient du vrai journal intime, on a le sentiment d'une caricature ou d'une prostitution: tout semble sonner faux"2. (2000, p.191).

Embora com algum preconceito (assumido pelo autor), Lejeune passou a acompanhar, e segundo o autor, a "varrer" exaustivamente a totalidade de diários on-line em francês, embora essa totalidade fosse (seja) movente, pois diários surgem e desaparecem todos os dias com a mesma facilidade. Na França, em novembro de 1999, eram cerca de 69 diários ativos e 42 inativos, em torno de 100 no total, enquanto a lista de diários em língua inglesa passava dos 1800 (LEJEUNE, 2000, p. 238).

O que nos interessa sobremaneira no estudo de Lejeune (2000) é a conclusão inicial a que o autor chega, quando começa seu levantamento sobre os diários on-line. Com o conhecimento aprofundado que tinha do universo do diarismo, tendo em vista suas publicações anteriores ${ }^{3}$, ao deparar-se com os diários on-line o autor observou que os ciberdiaristas provinham de ou tinham vínculos diretos ou indiretos com a informática, e, portanto, dominavam de certa forma a técnica necessária para se lançar nessa nova aventura. Não era tão óbvio nem tão acessível quanto pode parecer hoje:

l'idée de journal traverse quelqu'un qui connait l'informatique, plutôt que l'idée d'informatique quelqu'un qui pratique le journal. C'est donc un nouveau public, avec une autre culture, qui aborde une situation qui ressemble peut-être seulement au diarisme classique...4. (LEJEUNE, 2000, p.199)

\footnotetext{
2 Tradução livre: Quando a gente vem do verdadeiro diário íntimo, temos a sensação de uma caricatura ou de uma prostituição: tudo parece soar falso.

${ }^{3}$ Ver: Le Pacte autobiographique, Cher cabier..., Le Moi des demoiselles, Les Brouillons de soi.

${ }^{4}$ Tradução livre: A ideia do diário atravessa alguém que conhece a informática, mais do que a ideia da informática atravessa alguém que pratica o diarismo. É, portanto, um novo público, com outra cultura, que aborda uma situação que se parece talvez somente com diarismo clássico...
} 
Segundo Lejeune (2000, p. 92), foi na segunda metade do século XVII que o hábito da escrita quotidiana chamada "journal"5 dividiu-se em duas práticas de escrita: uma, a crônica social, com difusão cotidiana e impressa; a outra, a crônica pessoal, que, segundo o autor, manteve-se nos mesmos moldes, ou seja, inscrição manuscrita sem difusão ${ }^{6}$. Então temos aqui um ponto de ruptura com a prática da escrita íntima e a instauração de uma nova escrita, pública.

Essa divisão da escrita quotidiana em crônica social e crônica pessoal parece, de certa forma, ter-se desfeito com o surgimento dos diários on-line, ou blogs, como são chamados hoje, porque a escrita dos blogs reúne na evidência esses dois aspectos.

Nos primeiros anos do século XXI, houve uma especialização desses escritos, e atualmente existem blogs das mais diversas especialidades, sendo uma delas a divulgação científica, nosso foco de interesse. Tais blogs são escritos por pesquisadores, jornalistas científicos ou divulgadores em geral.

Em nossa dissertação de mestrado (OLIVEIRA, 2005), defendemos a hipótese da constituição dos blogs a partir do acontecimento discursivo do comentário, através de uma ruptura na rede de formulações, à qual o enunciado estava relacionado - a discursividade sobre os escritos pessoais -, possibilitando o surgimento de novos sentidos. Para tanto, levamos em conta o que Pêcheux (1990, p. 17) observa quando ele afirma que o acontecimento discursivo é o "ponto de encontro de uma atualidade e uma memória". Assim, o comentário aparece como uma regularidade constitutiva do funcionamento discursivo dos blogs na sua relação com o diário íntimo, que se movimenta, deslizando sentidos, instaurando uma nova - outras discursividade(s).

Essa passagem do diário pessoal para o blog foi possibilitada pela emergência de uma nova cultura, a cibercultura, emergência de um

\footnotetext{
${ }^{5}$ Lejeune (2000, p. 192) define « journal » como « habitude d'écrire à la main sur du papier chaque jour ce qui se passe autour de vous et éventuellement en vous ». Tradução livre: Hábito de escrever à mão sobre o papel cada dia o que se passa em torno de você e eventualmente o que se passa com você.

${ }^{6}$ Somente na segunda metade do século XIX a impressão de diários pessoais tornou-se um hábito. No início, de autores mortos, e mais tarde, os próprios autores ainda em vida publicaram seus diários (LEJEUNE, 2000).
} 
movimento de caráter técnico e social. Santaella (2003) situa a cibercultura dentro do que a autora chama de "seis eras culturais", sendo elas a cultura oral, a cultura escrita, a cultura impressa, a cultura de massas (dos meios de comunicação de massa), a cultura das mídias e a cultura digital ou cibercultura. Para essa autora, as transformações culturais são devidas aos tipos de signos que circulam nesses meios, aos tipos de mensagens e de processos de comunicação, e não somente aos meios. Assim, a autora coloca a linguagem como determinação central da comunicação e da cultura e tira a ênfase dos meios, das mídias.

Lévy, em seu livro Cibercultura, nos diz que a nomeação "ciberespaço" foi inventada por Gibson (2003) em seu romance de ficção científica Neuromante, de 1984, no qual a palavra designa "o universo das redes digitais, descrito como campo de batalha entre as multinacionais, palco de conflitos mundiais, nova fronteira econômica e cultural.” (LÉVY, 1999, p. 92). Essa nomeação foi logo incorporada pelos usuários das redes digitais. Lévy (1999, p. 92) define ainda ciberespaço como "o espaço de comunicação aberto pela interconexão mundial dos computadores e das memórias dos computadores", e afirma que o fundamental é que o ciberespaço não é uma infraestrutura, mas sim uma forma de usar e explorar as infraestruturas existentes.

Ao assimilar o ciberespaço a uma infra-estrutura, recobre-se um movimento social com um programa industrial. Movimento social, de fato, já que o crescimento da comunicação digital interativa não foi decidido por nenhuma multinacional, nenhum governo. (LÉVY, 1999, p. 194)

Da mesma forma, nos questionamos sobre a questão do "digital" e do "virtual". Quando Lévy (1999) aborda a questão do digital, ele o faz no capítulo intitulado "O digital ou a virtualização da informação", e aponta a digitalização como o fundamento técnico da virtualização. Quando digitalizamos imagens, sons, documentos etc., "traduzimos" essas informações em números (0 e 1), que não são acessíveis ao ser humano enquanto tal. Para o autor, a informação digital pode ser qualificada de virtual. Assim, por exemplo, temos a virtualização da informação. E outros movimentos de virtualização se desenvolvem, 
como a virtualização da comunicação, a virtualização das organizações, a virtualização da economia e da sociedade.

Lévy (1999, p. 47) define virtual como sendo "toda entidade 'desterritorializada', capaz de gerar diversas manifestações concretas em diferentes momentos e locais determinados sem, contudo, estar ela mesma presa a um lugar ou tempo em particular". Quando, no parágrafo anterior, o autor afirma que a informação digital pode ser qualificada de virtual, ele se refere ao fato de essa informação poder ser atualizada em qualquer lugar a partir do acesso de um internauta, tal como quando abrimos um link, uma imagem, etc..

Já Castells (1999), no tópico "a nova mídia e a diversificação da audiência de massa”, descreve os processos do que Santaella (2003) vai chamar de cultura das mídias, e que resumimos como a passagem da transmissão simultânea e uniforme de um número limitado de mensagens homogêneas a serem recebidas por uma audiência de massa, para uma multiplicação de fontes e mensagens onde a audiência torna-se seletiva e o relacionamento entre emissor e receptor fica mais individual (SABBAH, 1985 apud CASTELLS, 1999).

Acrescentamos ainda uma outra contribuição a partir do texto Cibernética e ação, de Moles (1973, p. 83), qual seja, a origem do termo 'cibernética'. Nesse caminho o autor nos apresenta algumas indicações interessantes:

A cibernética recebeu tal nome de Wiener e Von Neumann, por volta de 1945, depois da série de trabalhos do primeiro, a propósito dos processos de regulação, e dos trabalhos do segundo, acerca da analogia entre os mecanismos do cérebro humano e os dos primeiros computadores - aos quais Von Neumann deu importante contribuição. [...] Sem remontar a Platão, que caracterizou as atribuições do piloto (kubernetes) ou a Ampère, que viu a cibernética em termos de uma ciência do governo $[\ldots]$

Lemos (2002) considera que, mesmo que cibernética signifique, como vimos acima, controle e pilotagem, segundo ele, "a cibercultura 
não é o resultado linear de uma programação técnica do social"; para esse autor, ela parece ser, ao contrário, "o resultado de uma apropriação simbólica e social da tecnologia". E nesse sentido, concordamos com Lemos.

\section{ZOOM 2 - ANÁLISE DE DISCURSO E DIVULGAÇÃO CIENTÍFICA}

Para refletirmos sobre questões de autoria relacionadas à divulgação científica realizada/constituída através dos blogs, além de nos situarmos com relação à escrita dos diários e o deslizamento de sentido que possibilitou nossos contemporâneos blogs, já abordamos também a problemática do ciberespaço, e agora, portanto, se faz necessário refletir sobre os conceitos que norteiam nosso trabalho de leitura-interpretaçãocompreensão por meio de alguns princípios e procedimentos da Análise do Discurso, nosso dispositivo teórico-analítico. Não pretendemos rever todos os seus conceitos, nos apropriando apenas daqueles necessários para que, no batimento teoria-análise, possamos dar conta de nosso gesto de interpretação. Como nosso objetivo é compreender o funcionamento da autoria nos blogs de divulgação científica, trataremos a seguir dessas questões.

O primeiro conceito de que fazemos uso é o de autor. Autor é a função que o eu assume enquanto produtor de linguagem (GUIMARÃES; ORLANDI, 2001). Assim sendo, em Análise de Discurso não se trabalha com o autor real, empírico, no mundo, mas sim com a posição discursiva, com o sujeito do discurso exercendo sua função-autor. Desse ponto de vista, não nos interessa se o blogueiro/divulgador é jornalista ou pesquisador, mas sim, de qual posição discursiva ele fala/escreve. E como, para a Análise de Discurso, o discurso é produzido em uma rede de formações que estão em contínuo jogo de forças, interessa-nos saber quais formações discursivas estão funcionando em seu discurso e qual a formação discursiva dominante. Para, assim, compreendermos a posição-sujeito blogueiro e a questão da autoria jornalística.

Segundo Guimarães e Orlandi (2001), o autor é a instância de discurso mais sujeita ao controle social e onde há o maior apagamento 
do sujeito, que segue padrões, modelos institucionalizados, sendo-lhe cobrada a responsabilidade pelo que diz, e mais fortemente, a originalidade (ser a fonte) do seu dizer.

Outro conceito pertinente é o de formação discursiva, que é definido por Pêcheux (1997, p.160) como sendo aquilo que numa formação ideológica dada determina o que pode e deve ser dito, a partir de uma posição dada, em uma conjuntura dada. As várias posições do sujeito (que ele assume) podem representar diferentes formações discursivas no mesmo texto e a relação entre essas diferentes formações discursivas pode ser de várias ordens: de confronto, de sustentação mútua, de exclusão, de neutralidade aparente, de gradação (GUIMARÃES; ORLANDI, 2001, p. 57).

Se, de acordo com a Análise de Discurso, o sentido não existe em si, mas é determinado pelas posições ideológicas colocadas em jogo no processo sócio-histórico em que as palavras são produzidas, então nos questionamos sobre o sentido das palavras nos posts que analisamos. E neste caso, entendemos ser oportuno mobilizar o conceito de equívoco, e o fazemos a partir de Ferreira (2001, p. 15): "algumas de suas manifestações são as falhas, lapsos, deslizamentos, mal-entendidos, ambiguidades, que fazem parte da língua e representam uma marca de resistência e uma diferenciação em relação ao sistema".

Com estes parágrafos, pretendemos indicar a direção que tomamos com a leitura de nosso material de análise, e sem esquecermos que nosso lugar discursivo é a divulgação científica constituída através dos blogs. E esse "através dos blogs" merece atenção porque implica um funcionamento particular que deve ser considerado para a análise.

\section{ZOOM 3 - CORPUS E RECORTE}

Para este estudo constituímos um corpus composto pelos blogs do Anel de Blogs Científicos (ABC), do Laboratório de Divulgação Científica (LDC), da USP ${ }^{7}$. Para fins de análise, recorremos a um recorte

\footnotetext{
7 O Anel de Blogs Científicos do Laboratório de Divulgação Científica do DFM-FFCLRP-USP $(<$ http://dfm.ffclrp.usp.br/ldc $>$ ), coordenado pelo físico Osame Kinouchi Filho, tem como objetivo concentrar e disponibilizar links para blogs científicos, classificados por categorias, bem
} 
similar ao utilizado no projeto Núcleo de Jornalismo Científico - NJC Pronex $/ \mathrm{CNPq}^{8}$, qual seja, a presença da $61^{\mathrm{a}}$ Reunião Anual da SBPC nos blogs de divulgação da ciência 9 .

Tal delimitação, de nossa parte, foi se estabelecendo em várias etapas, pois o Anel de Blogs Científico constava, no dia em que fizemos a consulta, de 250 blogs. Em um primeiro momento fizemos a separação entre blogs brasileiros, portugueses e angolanos, ficando com 190 blogs brasileiros.

$\mathrm{Na}$ sequência, efetuamos uma busca um a um dos 190 blogs, através da ferramenta "pesquisa avançada", "procurar resultados com todas as palavras: XX" no "Domínio: apenas exibir resultados deste site: WWW" do buscador Google pelas palavras-chave "Reunião" e "SBPC", o que resultou em um mapeamento do que foi divulgado nos blogs sobre as Reuniões da SBPC como um todo, totalizando 25 blogs.

Em seguida, após a leitura desse material, verificamos tratar-se de posts das variadas reuniões da SBPC, e assim, filtramos mais uma vez, ficando então com 8 blogs, e 9 posts no total, que trataram especificamente da $61^{\text {a }}$ Reunião Anual da SBPC.

A seguir descreveremos os blogs em função de um critério já de análise, a questão do funcionamento da autoria, do sujeito-divulgador nos blogs de DC. Ou seja, como se constitui a posição-sujeito divulgador de ciência nesse espaço discursivo?

\section{ZOOM 4 - DESCRIÇÃO}

A fim de avançarmos na compreensão do funcionamento da autoria na divulgação científica através dos blogs, começamos por uma descrição dos posts que abordam a $61^{\mathrm{a}}$ Reunião Anual da SBPC. São eles:

como funcionar como agente catalisador para a expansão da blogosfera científica. Kinouchi também é responsável pelo blog SEMCIÊNCIA (<www.comciencias.blogspot.com>).

8 Projeto desenvolvido entre 1997 e 2004 pelos dois laboratórios do Núcleo de Desenvolvimento da Criatividade - Nudecri, o Laboratório de Estudos Urbanos - Labeurb, e o Laboratório de Estudos Avançados em Jornalismo - Labjor, da Unicamp.

${ }^{9}$ No caso do projeto NJC foi analisada a presença de notícias sobre a $50^{a}$ Reunião da SBPC em jornais e revistas de circulação nacional do período da reunião.

OLIVEIRA - O funcionamento da autoria... 
Blogeologia - é o blog de um geólogo da UFRGS e foi classificado pelo Anel de Blogs Científicos do Laboratório de Divulgação Científica da USP como pertencente à área do conhecimento "Ambiente e Ciências da Terra" 10 . O post tem como título "REUNIÃO ANUAL DA SBPC / TEATRO AMAZONAS 12/07" e foi publicado no dia 11 de julho de 2009. O texto (superfície textual) aparece dividido em três partes, sendo a primeira uma cópia integral do press-release (comunicado de imprensa) divulgado pela SBPC sobre a programação da Cerimônia de Abertura da $61^{a}$ Reunião ${ }^{11}$; a segunda também é uma cópia de outro press-release da SBPC, mais antigo, que fala sobre a abertura das inscrições para os minicursos da mesma reunião ${ }^{12}$; a terceira parte, que trata de uma pesquisa sobre a utilização da bioacústica como ferramenta para reconhecer e identificar na natureza a diversidade de aves, também foi inteiramente copiada do "JC e-mail 3792", de 26 de Junho de 200913, sem se mencionar a fonte.

No caso dos press-releases, eles têm a função de servir de material para pautas, ou mesmo serem publicados integralmente. Resumindo, a primeira parte descreve a cerimônia de abertura que vai acontecer, a segunda relata o fato de as inscrições estarem abertas e a terceira apresenta o trabalho de um pesquisador (e depois informa) que será tema de uma palestra no dia 14 de julho, durante a $61^{\text {a }}$ Reunião da SBPC.

Observa-se, aqui, um aspecto importante do funcionamento discursivo que estamos analisando, ou seja, todos os textos foram copiados de fontes jornalísticas, e, além disso, esse "copiar e colar" parece estar funcionando sob o efeito de uma prática muito difundida com o uso dos e-mails, o "encaminhar". Quando recebemos um e-mail, muito frequentemente temos a iniciativa de "repassar", mesmo sem sermos solicitados, a quem imaginemos interessar. Esse funcionamento nos parece bastante semelhante ao encontrado neste blog de pesquisador, quando o pesquisador copia e cola e disponibiliza o material em seu blog para seus leitores. Ambas as práticas mostram uma relação importante no movimento da autoria. Ocorre uma apropriação, ou seja, apaga-se o

\footnotetext{
10 Esse blog é o único nesta área e pode ser acessado através do endereço eletrônico <http://blogeologia.blogspot.com/2009/07/sons-da-floresta-revelam-que.html>.

${ }^{11}$ Confira-se: $<$ http://www.sbpcnet.org.br/site/imprensa/mostra.php?id $=1118 \&$ secao $=359>$.

${ }^{12}$ Confira-se: $<$ http://www.sbpcnet.org.br/site/imprensa/mostra.php?id $=1136 \&$ secao $=359>$.

${ }^{13}$ Confora-se: <http://www.jornaldaciencia.org.br/Detalhe.jsp?id=64327> .
} 
fato de ser esse texto de outra pessoa e passa a ser deste blog. Dito de outro modo, o movimento de autoria é textualizado: não lidamos com um autor como origem do dizer, ou o domínio do início, meio e fim, mas sim, com o movimento da autoria sendo textualizado; funcionando como se a informação estivesse no blog e não no jornal. Desse modo, quem acessa o blog não precisa acessar o jornal. O espaço virtual midiático (lugar do blog) e o espaço "real" (lugar da reunião da SBPC) passam a ser o mesmo, na medida em que virtualmente é fornecida a informação ao usuário real do espaço da SBPC.

Ciência na Mídia - é o blog de uma bióloga com especialização em jornalismo científico. Seu blog foi classificado como pertencente à área "Ciência Geral", primeiro de três blogs nesta área. ${ }^{14}$ O post tem como título "dia nacional da ciência", e foi publicado no dia 8 de julho de 2009. O post começa noticiando a escolha, através de decreto, do Dia Nacional da Ciência, proposto pelo Congresso Nacional, com a finalidade de incentivar a atividade científica. E continua, comentando a ausência de atividades comemorativas ao dia. Solicita aos que encontrarem algo na internet para avisarem. E para finalizar, aponta para a $61^{\mathrm{a}}$ Reunião da SBPC que acontece na semana seguinte, de 12 a 17 de julho de 2009, como sendo "o evento pro-ciência deste e de qualquer ano". Esse post tem seu funcionamento marcado pela escrita pessoal, com enunciados do tipo: "Bacana, né? Parece. Só que parece também que o dia não pegou". "[Manaus e Nova Yorque... tô precisando juntar mais dim-dim!]". Estamos chamando de escrita pessoal aquela escrita que foge ao exercício jornalístico de se propor como isento de opinião pessoal, remetendo-se visivelmente ao juízo do eu. Neste post vaza algo para além da divulgação científica. A blogueira, ao se inscrever, não se inscreve como jornalista ou divulgadora científica, e sim, estabelece uma relação "pessoal" com a questão da ciência, e o faz justamente pelo senso comum, quase como que uma contra-ciência.

Sem Rumo - é o blog de um jornalista científico que cobre as áreas de saúde e tecnologia. É o segundo blog da área do conhecimento "Ciência Geral". ${ }^{15} \mathrm{O}$ post tem como título "Experiências com animais: o

\footnotetext{
$14 \mathrm{O}$ blog pode ser acessado através do endereço eletrônico $<$ http://ciencianamidia.wordpress.com/2009/07/08/dia-nacional-da-ciencia/>.

${ }^{15} \mathrm{O}$ blog pode ser acessado pelo endereço <http://www.semrumo.com.br/index.php/experiaecircncias-com-animais-o-passado $>$.
}

OLIVEIRA - O funcionamento da autoria... 
passado e o futuro", e foi publicado no dia 14 de julho de 2009. O post traz trechos de uma matéria da Agência Brasil, que fez a cobertura do processo de regulamentação do uso de animais em pesquisas científicas, que foi discutido durante a reunião da SBPC, e comentários do blogueiro, intercalados aos trechos citados, sobre questões de economia e de ciência. Posiciona-se marcadamente contra determinados autores e a favor de outros. Esse funcionamento apresenta diferença com relação ao primeiro blog descrito, por trazer comentários do blogueiro intercalados aos trechos copiados de outras fontes. Esses comentários não são de cunho pessoal, ou seja, são comentários focados no texto, marcadamente há o efeito de neutralidade e informação, ao contrário do exemplo anterior, que era quase uma militância.

Xis-Xis - é o blog de uma jornalista e escritora com pós-graduação em divulgação científica. É o terceiro blog da área do conhecimento "Ciência Geral". ${ }^{16} \mathrm{O}$ post tem como título "Índios participarão da reunião da SBPC", e foi publicado no dia 24 de janeiro de 2009. O post comenta a participação/presença de índios na Campus Party e na Reunião Regional da SBPC que acontece em março, e afirma que esse encontro é preparatório para a $61^{\mathrm{a}}$ Reunião Anual da SBPC, que acontecerá em julho. O post tem um tom informal, caracterizado pela presença de comentários pessoais do blogueiro (escrita pessoal), com enunciados do tipo: "Óbvio que o encontro é preparatório para a Reunião Anual da SBPC"; "Tenho um amigo que possui parentes no Pará. Ele conta que [...]"; "Sexta, participei de uma mesa-redonda na Campus Party Verde". O funcionamento desse post difere do anterior por ser mais centrado no eu (escrita pessoal).

Pion - é o site da Sociedade Brasileira de Física e contém um blog, que conta com a colaboração de pesquisadores de várias instituições federais e estaduais do Brasil, e tem como propósito "levar noções básicas de física ao grande público e de contribuir para a formação de professores de física no Ensino Básico". É classificado como pertencente à área de "Ciências Físicas e Astronomia", da qual temos dois blogs. ${ }^{17}$

\footnotetext{
${ }^{16} \mathrm{O}$ blog pode ser acessaodo pelo endereço <http://scienceblogs.com.br/xisxis/2009/01/indiosparticiparao-da-reuniao-da-sbpc.php>.

${ }^{17}$ Disponível em: < http://www.pion.sbfisica.org.br/pdc/index.php/por/eventos/reuniao_da_ sbpc_2>.
} 
O post tem como título "61 a Reunião Anual da SBPC" e não apresenta data de publicação. O post é composto pelas informações práticas sobre o evento, tais como: data, descrição, local, e-mail, URL do evento e telefone. Esse post tem um funcionamento do tipo agenda.

Química de Produtos Naturais - é o blog de um professor do Instituto de Química da USP de São Carlos. É classificado como pertencente à área "Ciências Físicas e Astronomia", da qual faz parte junto com o blog anterior. Apresenta dois posts que abordam a $61^{\mathrm{a}}$ Reunião Anual da SBPC. O primeiro deles tem como título "Bioprospecção e química medicinal contra doenças negligenciadas", e foi publicado no dia 4 de julho de $2009 .{ }^{18}$ O post divulga a mesa-redonda "Biodiversidade e a busca por fármacos para doenças negligenciadas", que será realizada em dia e horário indicados, na $61^{\mathrm{a}}$ Reunião Anual da SBPC. E apresenta dois dos pesquisadores que participarão do evento. Divulga um trabalho em específico.

O segundo post tem como título "Uma luz, enfim?" e foi publicado no dia 14 de julho de $2009 .{ }^{19}$ O post introduz brevemente o que vai transcrever em seguida, ou seja, uma reportagem feita por Eduardo Geraque ${ }^{20}$, que é publicada na íntegra, sobre a obtenção de licenças para se estudar biodiversidade do Brasil, na qual consta uma declaração que o ministro Sérgio Rezende (MCT) fez quando de sua participação no primeiro dia da $61^{a}$ Reunião da SBPC. Funcionamento do tipo copiar e colar.

Blog do João Maria Andarilho Utópico. Pedagogia Magistério Psicopedagogia - é o blog de um professor formado pela Unoparvirtual (Campinas), classificado como pertencente à área "Educação e Blogs Didáticos", sendo o único nesta área a abordar a $61^{\text {a }}$ Reunião Anual da SBPC. Apresenta post com o título "Especialistas indicam os rumos que a EAD pode tomar a partir do modelo de regulamentação adotado para o setor", e foi publicado dia 22 de fevereiro de 2009.21 O post é cópia integral de texto publicado na revista Ensino Superior n. 125. ${ }^{22}$ Nenhum

\footnotetext{
18 Disponível em: <http://quiprona.wordpress.com/2009/07/04/bioprospeccao-e-quimicamedicinal-contra-doencas-negligenciadas $/>$.

${ }^{19}$ Disponível em: < http://quiprona.wordpress.com/2009/07/14/uma-luz-enfim/>.

${ }^{20}$ Folha Online. Ciência. "CNPq vai autorizar coleta de fauna e flora para pesquisa". 14/07/09.

21 Disponível em: <http://educacaodialogica.blogspot.com/2009/02/especialistas-indicam-osrumos-que-ead.html $>$.

${ }^{22}$ Disponível em: <http://revistaensinosuperior.uol.com.br/textos.asp?codigo=12332>.
}

OLIVEIRA - O funcionamento da autoria... 
assunto tratado no post aborda a Reunião da SBPC. Porém, na parte inferior aparece uma seção denominada "Mais notícias", na qual aparece um link, entre outros: "Prorrogado o prazo para inscrições da 61" reunião da SBPC", que encaminha para a notícia, na revista Ensino Superior, sobre a prorrogação do prazo para inscrições para a $61^{\mathrm{a}}$ Reunião da SBPC. Mesmo a seção "Mais Notícias" faz parte da revista e não do post. Funcionamento do tipo "copiar e colar". E fora o fato de ele encaminhar para uma revista de ensino superior, que o vincula à educação, em nenhum outro momento ele se inscreve, ou mostra quem é, ao contrário dos demais.

A Neurocientista de Plantão - é o blog de uma neurocientista, diretora do Laboratório de Neuroanatomia Comparada da UFRJ. Foi classificado como pertencente à área do conhecimento "Mente e Cérebro", sendo o único nesta categoria a abordar a 61 Reunião Anual da SBPC. O post apresenta o título "Encharcada de adenosina - e ainda não vi o Rio Negro...", e foi publicado dia 15 de julho de 2009.23 O post, em primeira pessoa, fala da ida da blogueira a Manaus para participar de uma mesa-redonda sobre divulgação científica na reunião da SBPC. E descreve suas atividades recentes, mesclando explicações sobre o funcionamento do cérebro com o seu estado de sono e questões pessoais familiares. A blogueira funde uma escrita pessoal, que diz respeito a eventos de sua vida quotidiana, com uma escrita de divulgação científica. O foco da blogueira é o seu eu, o que remete ao funcionamento do diário íntimo. A questão da DC entra quase que exclusivamente como pretexto. Sua participação na reunião da SBPC aparece entre parênteses como uma explicação do porquê de estar em Manaus. A blogueira narra sua chegada e a noite anterior, de intenso trabalho em artigo para periódico internacional de DC de renome, e novamente intercala um parêntese para dar algum detalhe. Sua escrita é constituída de três momentos, um no passado, um no presente e outro no futuro. Tal feito decorre do entrelaçamento de vários acontecimentos: participar de mesaredonda na reunião da SBPC (amanhã), ter passado a noite sem dormir viajando e escrevendo artigo de DC (ontem), estar cansada e com sono esperando o download de um programa de computador para enviar seu artigo de DC para a revista $\mathrm{X}$ (hoje). Intercaladas a essas informações

23 Disponível em: <http://www.suzanaherculanohouzel.com/journal/2009/7/15/encharcada-deadenosina-e-ainda-no-vi-o-rio-negro.html $>$. 
aparecem questões "científicas", que são tratadas de forma elementar, trocadas em miúdos, de forma a se fazer entender:

Meu cérebro deve estar completamente embebido em adenosina (o produto do funcionamento das suas células, que vai se acumulando enquanto estamos acordados e nos obriga dormir), com todos os neurônios e glia pedindo arrego (não dormi no avião; fiquei terminando o artigo, até a bateria do Vaio acabar. Ficou tããão bonitinho...).

Acho que vou dar uma chegadinha ali na beira d'água e ver se consigo botar a mão no Rio Negro (não é o Amazonas; eu fui conferir, claro, porque as aulas de geografia da escola ficaram lááá para trás, as redes que representavam 'Manaus-RioNegro' já tinham se desfeito. Peculiarmente, 'Rio Negro' evoca instantaneamente a palavra 'Solimões': essa associação ficou bem guardada, sabe-se lá por quê!).

Retomando a divisão da escrita quotidiana (“journal”) em duas, ocorrida na segunda metade de século XVII e citada por Lejeune ${ }^{24}$, que separou a crônica social da crônica pessoal, estes blogs apresentam visivelmente esses dois aspectos. Como vimos pelas descrições dos blogs apresentadas acima, temos presente nessa escrita tanto a crônica social quanto a crônica pessoal. $\mathrm{O}$ que nos remete à possibilidade de os blogs terem reunido novamente esses dois aspectos da escrita quotidiana que haviam sido separados.

\section{ZOOM 5 - RELAÇÕES DA DESCRIÇÃO}

A leitura dos blogs e a descrição feita nos permitem fazer algumas relações: do total de 9 posts, 2 são de jornalistas, 1 é de uma graduada em biologia, com mestrado em Neurociências e especialização em Divulgação Científica, 5 são de pesquisadores (UFRGS, UFSCAR, USPSC, USP-SC, UFRJ) e 1 é de um recém-graduado em Pedagogia.

${ }^{24}$ Citado anteriormente (Seção 2).

OLIVEIRA - O funcionamento da autoria... 
A partir da descrição feita também podemos agrupar esses blogs segundo três funcionamentos: os que fazem uso do "copiar e colar", que são 2 blogs de pesquisadores; os que fornecem dados sobre o evento, que são 2 blogs de pesquisadores e 1 de graduado; e um terceiro funcionamento, os que dizem algo sobre a reunião da SBPC, ou que podem estar funcionando sob o efeito de sentido da posição discursiva de divulgador científico; são 2 de jornalistas, 1 de pesquisador e 1 de mestre em Neurociência com especialização em DC.

Como consideramos para nosso recorte o funcionamento da autoria, interessa-nos analisar os blogs do terceiro grupo; embora os blogs desconsiderados também tenham sua autoria configurada de determinada forma, não as discutiremos aqui. Dentre os 4 blogs pertencentes a essa categoria temos 2 de jornalista e 2 de não jornalistas. E sendo o problema da autoria um aspecto relevante no funcionamento do discurso do jornalismo científico, para este texto trabalhamos com a questão do efeito-autor, como resultante do efeito de sentido da posição discursiva de divulgador científico nos blogs de DC. Assim, acabamos fechando em 225 blogs de DC e posteriormente em somente 1, porque o blog Sem Rumo está "fora do ar". Assim, nosso corpus final ficou sendo o blog Xis-Xis. E, agora sim, nos questionando: como é esse efeito de sentido diretamente marcado pela autoria de jornalista? Porque marcado pela autoria científica certamente é outro. Ou, dizendo de outro modo, que efeito de sentido a autoria de jornalista implica?

\section{ZOOM 6 - FORMAÇÕES DISCURSIVAS}

No post temos três formações discursivas em jogo: uma que constitui o discurso jornalístico, da notícia jornalística (FD1), outra que constitui o discurso urbano, ou de desidentificação com o que não é urbano (estranhamento do não urbano) (FD2), e uma terceira que constitui o discurso dos blogs, marcada pela escrita pessoal (do eu) (FD3). Nesse jogo de posições-sujeito, e de formações discursivas, a formação determinante é a urbana e de estranhamento (A), pois o post noticia a reunião da SBPC (B), o post se marca por uma escrita pessoal e se coloca na posição-sujeito blogueira $(\mathrm{C})$, mas, mais que isso, ele fica no

${ }^{25}$ Como o blog Sem Rumo está fora "fora do ar", nos ateremos exclusivamente ao blog Xis-Xis. 
estranhamento dessa realidade distante, desse planeta chamado Amazônia habitado por índios que se transportam em lanchas e que estranhamente/especialmente serão o público dessa reunião da SBPC. Os recortes que seguem constituem essas FDs:

(A)

- "Índios participarão da reunião da SBPC"

- "Não é apenas na Campus Party que os índios estão presente o que, aliás, mostra exatamente a miscigenação que é esse país, leia mais aqui."

- "O evento terá um público pouco comum em encontros científicos: povos indígenas, comunidades ribeirinhas e populações de fronteira."

- "Curiosidade. O Instituto de Natureza e Cultura, da Universidade Federal do Amazonas (Ufam), oferece cursos na cidade de Benjamin Constant onde é preciso pegar uma lancha de Tabatinga e navegar por 30 minutos."

- "Tenho um amigo que possui parentes no Pará. Ele conta que a realidade do Norte é completamente diferente da nossa."

(B)

- "A Sociedade Brasileira para o Progresso da Ciência (SBPC) realizará, de 17 a 20 de março próximo em Tabatinga, no Amazonas, uma reunião regional."

- "O tema central é "Conhecimento na fronteira" - em referência ao fato da cidade estar localizada no extremo oeste amazonense, onde o Brasil faz divisa com o Peru e a Colômbia."

- "Para Marilene Corrêa, reitora da Universidade do Estado do Amazonas (UEA), a reunião possibilitará um olhar da ciência para as necessidades e dificuldades da região."

- "Fonte: Foto do site Índios On-line." 
(C)

- “Óbvio que o encontro é preparatório para a Reunião Anual da SBPC, que será realizada em Manaus, de 12 a 17 de julho próximo, com o tema "Amazônia: Ciência e Cultura"."

- "Tenho um amigo que possui parentes no Pará. Ele conta que a realidade do Norte é completamente diferente da nossa."

- "Sexta, participei de uma mesa-redonda na Campus Party Verde - veja fotos aqui no Flick da Maria Carol- com outros blogueiros de meio ambiente e ciência. Rafael, do RNA mensageiro, perguntou: 'Você gosta de viver na Suíça ou no Brasil?' Seria o sudeste o Brasil?’”

Nossa hipótese era de que teríamos uma autoria de divulgador científico, com uma posição-sujeito divulgador de ciência determinante sobre todas as demais FDs, um efeito-autor, nos moldes desenvolvidos por Gallo (2001). Mas, como vemos, isso não ocorreu; do confronto dessas FDs não resultou uma dominante que caracterizasse uma nova ordem discursiva, ficando o sujeito na função-autor, função de todo sujeito que produz linguagem e se coloca na origem do seu dizer, ilusão necessária e constitutiva. Segundo Gallo (2001), o sujeito se identifica com uma FD “já lá”.

E o que isso quer dizer? Ou, dito de outro modo, que efeitos de sentido esse funcionamento produz? Em nosso entender, isso não significa que fizemos a pergunta errada. Porque, chegando a um efeitoautor ou não chegando, de um jeito ou de outro se produzem efeitos de sentido que merecem nossa atenção. Principalmente porque, em um objeto relativamente novo como os blogs de DC, interessa-nos observar seu funcionamento. Em segundo lugar, compreendemos, a partir de Gallo, que esse tipo de funcionamento movimenta os sentidos internos a uma ordem de discurso, mas, na contrapartida, garante a sua conservação. 


\section{ZOOM 7 - RELAÇÕES DAS FDS}

Em um primeiro momento consideramos a FD2 constituída como urbana, não por oposição ao rural, mas pela desidentificação com o que seja diferente do urbano. Já em um segundo momento, podemos reconhecer pelo funcionamento discursivo a configuração do par civilizado/selvagem, como constitutivo da FD2, pois quando temos os recortes discursivos "Índios participarão da reunião da SBPC", "não é apenas na Campus Party que os índios estão presente" e "o evento terá um público pouco comum em encontros científicos", estamos nos movimentando por sentidos afetados pela memória histórica relativa ao índio e a "incapacidade argumentativa de sua língua", como nos ajuda a demonstrar Pfeiffer (1995):

Os relatos dos missionários começam a mostrar a configuração das vilas, dos povoados, trabalhando nos limites da distinção entre o selvagem e o "civilizado". Nesta distinção, põe-se em relevo a questão da argumentação e dela vem a crítica da pobreza das línguas indígenas. Expliquemo-nos melhor: as línguas européias se adaptavam às necessidades crescentes de objetividade e clareza (como vimos em Haroche), ao mesmo tempo em que, por causa da instituição do direito, eram exploradas em suas possibilidades lógicas, para que melhor servissem à interpretação jurídica. A comparação com as línguas indígenas era logo feita. Se elas são pobres, tal como descreveram os viajantes e endossaram os missionários, de que modo os índios podem argumentar? Quais são as condições enunciativas que tais línguas oferecem para a interpretação? Pois bem, se falamos que a memória discursiva está sempre e continuamente nos afetando, não há obviedade maior do que o fato de que esta crítica histórica nos afeta até hoje enquanto sujeitos de linguagem (PFEIFFER, 1995, p. 59-60).

E como esse índio, incapaz de ser objetivo e claro, pode falar do/no lugar científico? Se é no equívoco que o sujeito se mostra, vejamos a sequência do enunciado que citamos acima, "Não é apenas na Campus Party que os índios estão presente - o que, aliás, mostra 
exatamente a miscigenação que é esse país, leia mais aqui" (grifo nosso). "Miscigenação" aparece significando a presença de índios em um evento de tecnologia e cultura digital, e não outra coisa, tal como encontramos em dicionários portugueses e brasileiros: 1) "procriação de indivíduos de raça mista, especialmente provindos do cruzamento de brancos e negros"26; ou ainda, 2) "reprodução por conjugação de indivíduos de raças ou, mesmo, espécies diferentes" 27 . Essa falha, esse equívoco nos parece bastante significativo, pois faz eco no discurso da colonização: em 4 de abril de 1755, D. José, rei de Portugal, assina um decreto autorizando a miscigenação de portugueses e índios. A filiação a uma formação discursiva colonialista, em nosso entender, aí se configura.

Como sabemos, o texto é atravessado por várias formações discursivas, existindo a dominância de uma formação sobre as demais, que resulta no efeito da unidade do texto. Neste caso, a função de autoria jornalística está funcionando sob o efeito do discurso colonialista urbano, uma vez que entendemos que é a FD urbana colonialista que domina as demais FDs em jogo.

\section{FULL SCREEN - TELA CHEIA - CONCLUSÃO}

Tomando como ponto de partida nossa pergunta inicial que diz respeito ao modo como se constitui a posição-sujeito divulgador de ciência nesse espaço discursivo, considerando os recortes feitos e as especificidades do ciberespaço, ou, melhor dizendo, as condições de produção do discurso jornalístico nas novas TICs, encontramos um funcionamento presente nos blogs como um todo e no blog analisado em especial, que é o copiar e colar. Esse funcionamento visto à luz das novas tecnologias aparece como constitutivo de uma nova forma de relação do sujeito com a escrita, um movimento na autoria, que atualiza sentidos que já circulavam sob a forma da citação e que agora circulam sob uma nova forma, apropriados, incorporados ao texto como se fossem ditos pela primeira vez, "satisfazendo" o mito da originalidade, tão caro no funcionamento da autoria.

\footnotetext{
${ }^{26}$ Dicionário Priberam da Língua Portuguesa. Disponível em: <http://www.priberam.pt/dlpo/>.

27 Michelis. Moderno Dicionário da Língua Portuguesa. Disponível em: $<$ http://michaelis.uol.com.br/>.
} 
Ainda sobre a autoria na divulgação científica, apontamos para mais duas questões: a) um funcionamento novo, que incorpora uma prática (da internet) contemporânea à escrita dos blogs de DC, que é o copiar e colar (copy and paste), que representa uma apropriação do texto pelo blogueiro; apaga-se o fato de o texto ser de outra pessoa. Não lidamos mais com um autor como origem do dizer. O movimento da autoria é, assim, textualizado; b) $\mathrm{O}$ que foi notícia sobre a $61^{\circ}$ Reunião Anual da SBPC no material analisado foram os índios e não diretamente a ciência, ou o encontro da Sociedade Brasileira para o Progresso de Ciência.

Com relação à(s) formação(ões) discursiva(s), temos, no material analisado, uma FD dominante urbana colonialista caracterizada pelo estranhamento da cultura do outro (do índio), e a colocação desse sujeito (o índio) não no lugar de quem fala sobre os seus problemas, mas sim no lugar de quem é falado por eles, marcando, dessa forma, sua posiçãosujeito a partir dessa diferença.

$\mathrm{O}$ que a $\mathrm{AD}$ nos proporcionou neste trabalho foi um dispositivo de leitura e interpretação que nos possibilitou visibilizar (tornar visíveis) relações de sentido e procedimentos históricos de apagamento do índio no/do processo de produção do saber. Mas, e o que tudo isso tem a ver com o modo como se constitui a posição-sujeito divulgador de ciência? Em nosso entender, nesse novo aparato técnico e social, que é a internet, e que vem modificando as relações com a escrita e com o conhecimento, no movimento dos sentidos, novos e velhos sentidos, está funcionando e significando essa posição de sujeito divulgador.

\section{REFERÊNCIAS}

CASTELlS, M. A sociedade em rede. São Paulo: Paz e Terra, 1999.

FERREIRA, M. C. L. Glossário de termos de Análise do Discurso. Instituto de Letras, UFRGS, 2001.

GALLO, S. Autoria: questão enunciativa ou discursiva. Linguagem em (Dis)curso, v.1, n.2, p. 61-70, jan./jun. 2001.

GIBSON, W. Neuromancer. São Paulo: Editora Aleph, 2003. 
GUIMARÃES, E.; ORLANDI, E. Unidade e dispersão: uma questão do texto e do sujeito. In: Discurso e Leitura. São Paulo: Cortez, 2001.

LEJEUNE, P. Cher écran: Journal personnel, ordinateur, Internet. Paris: Seuil, 2000.

LEMOS, A. Cibercultura: tecnologia e vida social na cultura contemporânea. Porto Alegre: Sulina, 2002.

LÉVY, P. Cibercultura. São Paulo: Editora 34, 1999.

MOLES, A. Cibernética e ação. In: EPSTEIN, I. (Org.) Cibernética e comunicação. São Paulo: Cultrix, 1973.

OLIVEIRA, S. de M. de. Diário íntimo e/ou blog: o mesmo e o diferente na cultura do ciberespaço. 2005. Dissertação (Mestrado em Letras)—Programa de Pós-graduação em Letras, Universidade Federal de Santa Maria, Santa Maria, 2005.

PÊCHEUX, M. Semântica e discurso: uma crítica à afirmação do óbvio.

Campinas: Ed. da Unicamp, 1997.

O discurso: estrutura ou acontecimento? Campinas: Pontes, 1990.

PFEIFFER. C.. Que autor é este? 1995. Dissertação (Mestrado em

Linguística)-Programa de Pós-graduação em Linguística, Universidade Estadual de Campinas, Campinas, 1995.

SANTAELLA, L. Da cultura das mídias à cibercultura: o advento do póshumano. Revista FAMECOS, Porto Alegre, n. 22, dez. 2003.

Recebido em 10/10/11. Aprovado em 22/12/11.

Title: The functioning of authorship in scientific dissemination blogs

Author: Simone de Mello de Oliveira

Abstract: The present paper reflects on the discursive functioning of scientific dissemination blogs, while challenging the mode of authorship building in the context of New Technologies of Information and Communication. Thus, here are analyzed those scientific dissemination blogs that are part in the Anel de Blogs Cientificos da USP, and selected the posts about the 61st Annual Meeting of the SBPC (Brazilian Society for Scientific Development). The adopted analytical procedures were those of the French line of Discourse Analysis, which allowed the observation of a functioning that incorporates an Internet procedure, copy and paste, which represents an appropriation of texts by the blogger; the fact that the text belongs to another person is erased. Consequently, one does not deal with an author as the origin of the saying anymore.

Key words: Authorship. Blogs. Scientific dissemination. 
Titulo: El funcionamiento de la autoría en los blogs de divulgación cientifica Autor: Simone de Mello de Oliveira

Resumen: Este articulo se propone a pensar el funcionamiento discursivo de los blogs de divulgación cientifica, colocando en cuestión el modo de constitución de la autoria, en el contexto de las Nuevas Tecnologías de la Información y de la Comunicación (NTICs). Para tanto, analizamos los blogs de divulgación cientifica del Anillo de Blogs Cientificos de la USP y recortamos los posts sobre la $61^{\circ}$ Reunión Anual de la SBPC. Tomamos como procedimientos de análisis aquellos presentados por el Análisis de discurso de línea francesa. Y a partir del análisis, podemos observar un funcionamiento que incorpora una práctica de la internet, que es el copiar y pegar, y que representa una apropiación de textos por el bloguero; se borra el hecho del texto ser de otra persona. Luego, no lidiamos más con un autor como origen del decir.

Palabras-clave: Autoría. Blogs. Divulgación cientifica.

OLIVEIRA - O funcionamento da autoria... 